Queries for ecol-89-07-30

This manuscript/text has been typeset from the submitted material. Please check this proof carefully to make sure there have been no font conversion errors or inadvertent formatting errors. Allen Press. 


\title{
MASS EFFECTS MEDIATE COEXISTENCE IN COMPETING SHREWS
}

\author{
Jérôme Guélat, Julie Jaquiéry, ${ }^{1}$ Laura Berset-Brändli, Ester Pellegrini, Ruben Moresi, Thomas Broquet, \\ Alexandre H. Hirzel, and Nicolas Perrin \\ Department of Ecology and Evolution, University of Lausanne, CH-1015 Lausanne, Switzerland
}

\begin{abstract}
Recent developments in metacommunity theory have raised awareness that processes occurring at regional scales might interfere with local dynamics and affect conditions for the local coexistence of competing species. Four main paradigms are recognized in this context (namely neutral, patch-dynamics, species-sorting, and mass-effect), that differ according to the role assigned to ecological or life-history differences among competing species, as well as to the relative time scale of regional vs. local dynamics. We investigated over four generations the patterns of regional and local coexistence of two species of shrews (Crocidura russula and Sorex coronatus) sharing a similar diet (generalist insectivores), in a spatially structured habitat at the altitudinal limit of their distributions. Local populations were small and regional dynamics were strong, with high rates of extinction and recolonization. Niche analysis revealed significant habitat differentiation on a few important variables, including temperature and availability of winter resting sites. In sites suitable for both species, we found instances of local coexistence with no evidence of competitive exclusion. Patterns of temporal succession did not differ from random, with no suggestion of a colonization-competition trade-off. Altogether, our data provide support for the mass-effect paradigm, where regional coexistence is mediated by specialization on different habitat types, and local coexistence by rescue effects from source sites. The strong regional dynamics and demographic stochasticity, together with high dispersal rates, presumably contributed to mass effects by overriding local differences in specific competitive abilities.
\end{abstract}

Key words: coexistence; colonization; competition; Crocidura russula; habitat differentiation; habitat suitability model; mass effect; regional vs. local dynamics; shrews; Sorex coronatus; source-sink dynamics; stochasticity.

\section{INTRODUCTION}

Much of community theory to date has focused primarily on processes affecting species interactions at a local scale, as modeled by classical population-dynamics equations (Lotka-Volterra type and extensions; Lotka 1924, Volterra 1926). Under these settings, and notwithstanding interactions with higher trophic levels, species coexistence is largely mediated by resource partitioning. Competitive exclusion can only be avoided if niche displacement depresses interspecific competition below intraspecific levels (Chesson 2000a). However, recent empirical and theoretical studies have raised awareness that processes occurring at larger spatial scales might interfere with local dynamics and affect conditions for local coexistence (reviewed in Amarasekare 2003, Leibold et al. 2004). The concept of metacommunity is now emerging as a relevant tool to formalize interactions among regional and local scales, shedding new light on reasons why competitors coexist more often than expected (Holyoak et al. 2005).

Four main lines of research are to be distinguished within this framework (Leibold et al. 2004). The neutral

Manuscript received 1 June 2007; revised 6 September 2007; accepted 13 November 2007. Corresponding Editor: T. J. Valone.

${ }^{1}$ Corresponding author. E-mail: julie.jaquiery@unil.ch
(NE) paradigm (Hubbell 2001) assumes that interacting species differ neither in ecology nor in life history. In the absence of extrinsic processes (speciation or immigration from outside the metacommunity), competitive exclusion should eventually drive to extinction all species but one. However, as transient dynamics can be very long, low rates of speciation or immigration are enough to maintain some diversity at equilibrium. Whether diversity accrues within or among sites depends on the relative forces of drift (which accelerates the local loss of species) and dispersal (which homogenizes species distributions and thus promotes local coexistence).

The patch-dynamics (PD) paradigm (e.g., Levins and Culver 1971, Tilman 1994) considers multiple identical patches that undergo stochastic or deterministic extinctions counterbalanced by dispersal. It differs from the null (neutral) model by assuming that regional coexistence is mediated by life-history differences among species (namely a trade-off between competitive ability and dispersal). Models along this line often assume that local dynamics occur on a shorter time scale than extinction-colonization dynamics (patch-occupancy models), which limits the scope for local coexistence.

The two other paradigms assume that patches differ in conditions (which allows regional coexistence through specialization on different patch types), but assign different roles to dispersal. In the species-sorting (SS) 
paradigm (Leibold 1998, Chase and Leibold 2003), intra-patch population dynamics occur on a shorter time scale than colonization-extinction processes, so that locally superior species have ample time to outcompete rivals. The scope for local coexistence is thereby limited, and species distributions closely match local conditions (Cottenie et al. 2003, Leibold and Norberg 2004). In the mass-effect (ME) paradigm (Levin 1974, Shmida and Wilson 1985, Holt 1993, Pulliam 2000, Mouquet and Loreau 2002), by contrast, local and regional processes occur at the same time scale, which allows dispersal to quantitatively affect local dynamics and promote local coexistence (extinction rates of competitively inferior species are reduced by source-sink dynamics and rescue effects).

Stochastic processes may obviously affect population dynamics in all four paradigms. On the one hand, stochasticity is expected to accelerate the local loss of diversity through increased drift, in the same way that genetic drift accelerates allele fixation. On the other hand, it makes the outcome of competitive interactions less predictable. Random events in small populations may actually override possible differences in specific competitive abilities (SS or ME models), in the same way that genetic drift may override possible differences in allelic fitness (Orrock and Fletcher 2005).

To sum up, ME and SS differ from NE and PD by assuming that intrinsic differences among local sites affect the regional distribution of competing species; SS differs from ME by assuming different time scales for local and regional processes; and PD differs from NE by assuming a trade-off between colonization and competitive abilities. Even though real metacommunities are not expected to conform to one single paradigm, the classification and schematization just discussed provide a useful framework to delineate processes and address relevant empirical issues (Leibold et al. 2004).

In the present study, we focus on two species of shrews sharing a similar diet (generalist insectivores), and investigate the temporal patterns of local and regional coexistence in a spatially structured habitat. In order to delineate which of the four metacommunity paradigms best explains the observed patterns, we address the following questions. Do the species under study occupy sites that differ according to ecologically relevant factors (as expected from SS and ME, against $\mathrm{PD}$ and NE)? Do they differ in colonization or competitive abilities (as expected from PD, against $\mathrm{NE}$ )? Are regional processes (immigration-emigration) strong enough to prevent competitive exclusion from sites otherwise suitable for both species (as expected from ME, against SS)? As it turns out, responses to these questions point to the mass effect (ME) paradigm as the most appropriate model to account for observed patterns of local and regional coexistence in the system under study.

\section{Methods}

Study species

The two soricid shrews, Crocidura russula (Hermann, 1780) and Sorex coronatus (Millet, 1828), closely resemble each other in terms of feeding ecology, morphology, and life history. The two species display very similar body mass (C. russula, 9-12 g, S. coronatus, 9-11 g), the clearest discriminating morphological character being tooth coloration (the enamel is reddish in $S$. coronatus and whitish in C. russula). Both are ground-foraging insectivores, sharing a generalist diet consisting mostly of arthropods, worms, and mollusks (Bever 1983, Castien and Gosalbez 1995, Hausser 1995). Shrews are characterized by a highly elevated rate of metabolism, which imposes very important energetic needs (Genoud 1985). Owing to the seasonality in prey availability, winter food shortage constitutes the major source of mortality that limits natural populations (Genoud and Hausser 1979, Bouteiller and Perrin 2000, Butet et al. 2006). Competition for food is thus likely to play a crucial role in species interactions. Other potential competitors (i.e., other shrews of the genus Sorex and Neomys) are virtually absent from the study area (see Results). Predators are few and similar for both species (mainly domestic cats and nocturnal raptors such as the Common Barn Owl, Tyto alba; Indelicato [2000]). Finally, both species are annual breeders with juvenile dispersal (Churchfield 1990, Favre et al. 1997).

Widespread in western Europe, these shrews have a lowland distribution in Switzerland, usually found below $1000 \mathrm{~m}$ above sea level, a.s.l. (Hausser 1995). Crocidura russula is preferentially anthropophilic below $600 \mathrm{~m}$ and strictly so at higher altitudes (Genoud 1985), relying on thermally favorable sites (farms, stables, and compost heaps) to meet the energetic needs of the cold season (Genoud and Hausser 1979). Sorex coronatus is found in more diverse habitat types including forests, hedges, and meadows (Genoud 1982). However, despite slightly divergent preferences, many habitats are suitable for both species (Genoud 1982, Butet et al. 2006). Given the similarities in the trophic niche and the high energetic requirements, strong competition is expected at the local scale. Some authors (Croin Michielsen 1966, Genoud 1982; J. Hausser, unpublished data) indeed suggested that $S$. coronatus might be excluded from anthropophilic areas by $C$. russula, based on the observations that the species are only rarely found in syntopy, despite being sympatric over a large part of western Europe (Genoud 1985) and that S. coronatus is found next to human settlements in northern Europe, where C. russula is absent (Genoud 1982). Competitive dominance by $C$. russula might point to a patchdynamics component in specific interactions (colonization vs. competition trade-off). To what extent dispersal suffices to counteract competitive exclusion and allow local coexistence remains an open empirical question. 


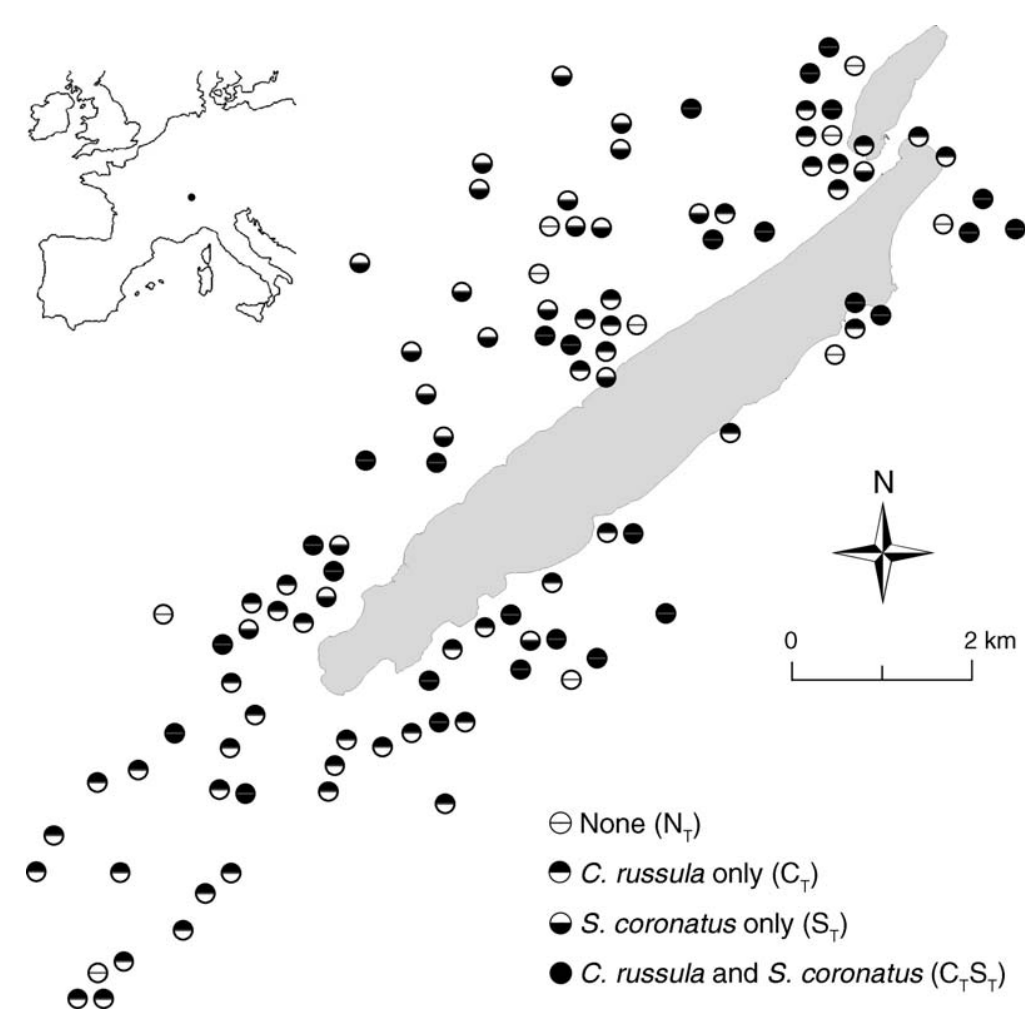

FIG. 1. Map of the sampled sites. Open circles represent sites that remained unoccupied throughout the study $\left(\mathrm{N}_{\mathrm{T}}\right)$. Solid circles $\left(\mathrm{C}_{\mathrm{T}} \mathrm{S}_{\mathrm{T}}\right)$ indicate sites where both shrew species (Crocidura russula, $\mathrm{C}$; Sorex coronatus, $\mathrm{S}$ ) occurred at least once (but not necessarily within the same year). Half-solid, half-open circles are sites where only one of the two species was caught throughout the study $\left(\mathrm{C}_{\mathrm{T}}\right.$, C. russula only; $\mathrm{S}_{\mathrm{T}}, S$. coronatus only). Subscript ${ }_{\mathrm{T}}$ refers to the site occupancy pattern over the four-year survey. The lake, Lac de Joux, is light gray.

\section{Field sampling}

The study area was located in the Vallée de Joux $\left(6^{\circ} 15^{\prime} \mathrm{E}, 46^{\circ} 37^{\prime} \mathrm{N}, 1000-1300 \mathrm{~m}\right.$ a.s.l.), Switzerland, at the upper altitudinal limit of both species. C. russula is strictly anthropophilic at these altitudes (Genoud 1985). Harsh environmental conditions might simultaneously increase energetic needs and decrease prey abundance, thus enhancing competition for food. Demographic and environmental stochasticity are also a priori likely to play a role in their distribution patterns. Abundances were monitored in summer (August to September) in 106 sites (62 in 2003; 84 in 2004, 2005, and 2006), over a $6 \times 14 \mathrm{~km}$ area (Fig. 1). Sampling sites consisted of $20 \times$ $20 \mathrm{~m}$ areas within private gardens. These were always adjacent to human habitations, and usually comprised some lawn, a vegetable garden, a compost pile, wooden piles, stone walls, and hedges. Of these sites, 42 were sampled over all four years, 40 sites over three consecutive years, two sites over two consecutive years, and 22 sites only once. It should be noted that our choice of sampling sites (gardens) preferentially focused on $C$. russula, and that $S$. coronatus may occupy localities outside human settlements. Individuals were livetrapped using 20 Longworth small-mammal traps per site (Longworth Scientific Instruments, Abingdon, UK), baited with Tenebrio molitor (yellow mealworm) larvae. After a pre-baiting period of 2-4 days, each site was visited four times during two consecutive days. The traps were opened daily at around 06:30 hours, checked at 10:00, and again at 13:30 hours, before being closed for the night. All caught individuals were sexed, aged, individually marked by toe clipping, and immediately released.

A site was considered as occupied by species A if at least one individual was captured. Site colonization rate $\left(\mathrm{yr}^{-1}\right)$ was estimated as the number of annual transitions from an empty to an occupied state (i.e., the sum of cases in which a site was empty in year $t$ and occupied in year $t+1$ ), divided by the total number of transitions from an empty state (i.e., the sum of cases in which a site was empty in year $t$ and monitored in year $t+1$ ). A site extinction rate was similarly estimated as the number of transitions from an occupied to an empty state, divided by the total number of transitions from an occupied state. For both rates, analysis was restricted to the set of sites that were occupied at least once over the four years.

\section{Habitat modeling}

Habitat preferences of both species were modeled with the Ecological Niche Factor Analysis (ENFA, Biomapper 3.2; Hirzel et al. 2002, 2004a) at 25-m resolution. 
TABLE 1. Scores of the environmental variables on the first four axes of the Ecological Niche Factor Analysis (ENFA) for the shrews Sorex coronatus (S.c.) and Crocidura russula (C.r.).

\begin{tabular}{|c|c|c|c|c|c|c|c|c|c|}
\hline \multirow[b]{2}{*}{ Variable } & \multicolumn{2}{|c|}{ Marginality } & \multicolumn{2}{|c|}{ Specialization 1} & \multicolumn{2}{|c|}{ Specialization 2} & \multicolumn{2}{|c|}{ Specialization 3} & \multirow[b]{2}{*}{ Range (units) } \\
\hline & S.c. & C.r. & S.c. & C.r. & S.c. & C.r. & S.c. & C.r. & \\
\hline BUILD $†$ & 0.74 & 0.76 & -0.25 & 0.01 & 0.04 & -0.10 & -0.22 & 0.16 & $0.7-33.5$ (no. buildings) \\
\hline ELEV† $\dagger$ & -0.34 & -0.21 & -0.87 & -0.73 & 0.56 & 0.08 & -0.03 & 0.67 & $1008-1299(\mathrm{~m})$ \\
\hline EAST $\dagger$ & 0.25 & -0.01 & -0.06 & -0.02 & 0.20 & -0.32 & -0.13 & 0.07 & -0.99 to 1 \\
\hline FROST $\ddagger$ & 0.24 & -0.05 & -0.28 & -0.18 & -0.41 & 0.02 & 0.39 & -0.38 & 9-24 (days) \\
\hline NDVI§ & -0.05 & -0.24 & 0.23 & 0.33 & 0.48 & -0.34 & 0.11 & 0.55 & -0.02 to 0.5 \\
\hline NORTH $\dagger$ & -0.14 & -0.01 & 0.10 & 0.23 & -0.14 & 0.14 & 0.43 & 0.05 & -1 to 1 \\
\hline WHAB $\uparrow$ & 0.46 & 0.56 & -0.02 & -0.17 & 0.47 & -0.11 & 0.27 & 0.24 & 0-27.2 (building/m²) \\
\hline WRAD & 0.04 & 0.00 & 0.19 & 0.49 & 0.09 & 0.87 & 0.72 & 0.14 & $3612-10346(\mathrm{~kJ} / \mathrm{d})$ \\
\hline
\end{tabular}

Notes: A positive marginality coefficient indicates that the species is found at values higher than average. Only absolute values matter for the specialization axes (see Hirzel et al. 2002). BUILD, number of habitations $(f)$ within a $100 \mathrm{~m}$ radius, weighted by distance $(d)$ to the closest building, $f(\exp [-d / 100])$; ELEV, elevation; EAST, easterly aspect; FROST, number of frost days per year; NDVI, normalized difference vegetation index (correlated with vegetation biomass); NORTH, northerly aspect; WHAB, number of buildings occupied in winter within a $100 \mathrm{~m}$ radius; WRAD, average solar radiations in winter (December to February). Units are given when applicable.

$\dagger$ Federal Office of Topography, 3084 Wabern, Switzerland.

\$ Provided by N. E. Zimmermann and F. Kienast from the Swiss Federal Institute for Forest, Snow and Landscape Research, 8903 Birmensdorf, Switzerland.

$\S$ Advanced Spaceborne Thermal Emission and Reflection Radiometer, NASA, Jet Propulsion Laboratory, California Institute of Technology, Pasadena, California, USA. 〈http://asterweb.jpl.nasa.gov/index.asp $\rangle$

This multivariate analysis extracts a series of independent factors (linear combinations of environmental variables) that maximize the marginality and specialization of a focal species, relative to a reference area. Marginality measures how much the environmental conditions in "presence" sites depart from average, and specialization measures the narrowness of their distributions, relative to that of reference sites. ENFA only requires presence data, and thus is often applied when species absences do not necessarily reflect habitat unsuitability (Hirzel et al. 2001, 2004b, Reutter et al. 2003, Brotons et al. 2004, Engler et al. 2004, Chefaoui et al. 2005). It is well adapted to our case, where absences may originate from stochastic demographic processes or competitive exclusions rather than environmental incompatibilities.

To reflect the sampling pattern, the study area was restricted to a 200-m buffer around human habitations. Eight environmental variables (Table 1) were chosen in accordance with the ecology of our study species (Hausser 1995): three topographic variables (altitude and northerly and easterly aspects); two climatic variables (winter solar radiation and number of frost days per year); two anthropogenic variables (number of winter-inhabited buildings within a $100 \mathrm{~m}$ radius, and number of buildings within a $100 \mathrm{~m}$ radius weighted by distance); and one biotic variable measuring plant productivity (normalized difference vegetation index, NDVI; Rouse et al. 1973). Each site where C. russula (respectively, S. coronatus) occurred at least once during the survey was considered as a presence point in the $C$. russula (respectively, $S$. coronatus) ENFA analysis. The marginality factor plus all factors explaining more than $10 \%$ of specialization were used to build habitat suitability maps. This provided an index of habitat suitability to $C$. russula $\left(H_{\mathrm{C}}\right)$ and to $S$. coronatus $\left(H_{\mathrm{S}}\right)$ for each site.

The quality and robustness of the models were evaluated by the continuous Boyce index as implemented in Biomapper 3.2, using $k$-fold cross-validation (Fielding and Bell 1997). This index measures how better than chance expectation a model is (for more details, see Hirzel et al. 2006). The presence data set was split into $k$ partitions (for $C$. russula, $k=6$; for $S$. coronatus, $k=4)$; then a new model was built with $k-1$ partitions (calibration data set) and was validated with the omitted one (evaluation data set). We repeated this procedure for the $k$ independent partitions to get mean and standard deviation of the Boyce index (Hastie et al. 2001).

\section{Site differentiation and spatial exclusion}

The overall degree of differentiation or exclusion between $C$. russula and $S$. coronatus was estimated by the kappa statistic, $\kappa$ (Cohen 1960), which compares the agreement between two categorical variables (here, species occurrences, 0 or 1) in the same way as correlation coefficients do for quantitative variables

$$
\kappa=\frac{N \sum_{i=0}^{1} x_{i i}-\sum_{i=0}^{1} x_{i .} x_{. i}}{N^{2}-\sum_{i=0}^{1} x_{i .} x_{. i}}
$$

where $N$ represents the total number of observations, $x_{11}$ is the number of co-occurrences, $x_{00}$ is the number of times both species where absent, $x_{1}$. (respectively, $x_{\cdot 1}$ ) stands for the number of times $C$. russula (respectively, $S$. coronatus) was present, and $x_{0}$. (respectively, $x_{0}$ ) is the number of times $C$. russula (respectively, $S$. coronatus) was absent. Kappa varies from -1 (the two 
TABLE 2. Patterns of site occupancy by shrew species (Crocidura russula, C; Sorex coronatus, S) over the four study years.

\begin{tabular}{|c|c|c|c|c|c|c|}
\hline \multirow{2}{*}{$\begin{array}{c}\text { Site } \\
\text { occupation }\end{array}$} & \multicolumn{4}{|c|}{ Number of sites } & \multirow[b]{2}{*}{ Site code } & \multirow[b]{2}{*}{ All years } \\
\hline & 2003 & 2004 & 2005 & 2006 & & \\
\hline $\mathrm{C}_{0} \mathrm{~S}_{0}$ & 13 & 29 & 24 & 30 & $\mathrm{~N}_{\mathrm{T}}$ & 10 \\
\hline $\mathrm{C}_{1} \mathrm{~S}_{0}$ & 28 & 35 & 36 & 28 & $\mathrm{C}_{\mathrm{T}}$ & 46 \\
\hline $\mathrm{C}_{0} \mathrm{~S}_{1}$ & 16 & 16 & 17 & 24 & $\mathrm{~S}_{\mathrm{T}}$ & 22 \\
\hline $\mathrm{C}_{1} \mathrm{~S}_{1}$ & 5 & 4 & 7 & 2 & $\mathrm{C}_{\mathrm{T}} \mathrm{S}_{\mathrm{T}}$ & 28 \\
\hline Total & 62 & 84 & 84 & 84 & Total & 106 \\
\hline
\end{tabular}

Notes: $\mathrm{C}_{0} \mathrm{~S}_{0}$, sites with no species during the year; $\mathrm{C}_{1} \mathrm{~S}_{0}$ (respectively, $\mathrm{C}_{0} \mathrm{~S}_{1}$ ), sites with $C$. russula (respectively, $S$. coronatus) only; $\mathrm{C}_{1} \mathrm{~S}_{1}$, sites with both species present within the same year. $\mathrm{N}_{\mathrm{T}}$, number of sites that remained unoccupied throughout the study; $\mathrm{C}_{\mathrm{T}}$ (respectively, $\mathrm{S}_{\mathrm{T}}$ ), number of sites where $C$. russula only (respectively, $S$. coronatus only) were caught throughout the study; $\mathrm{C}_{\mathrm{T}} \mathrm{S}_{\mathrm{T}}$, number of sites where both species occurred at least once (but not necessarily within the same year). Subscript $T$ refers to the site occupancy pattern over the four-year survey.

species are never found together), through 0 (independence), to 1 (always together). Kappa values were computed both over the four-year study period and for each year separately. To test significance, yearly observations at a site were bootstrapped (10000 replicates), and observed kappa values were considered significant if the $95 \%$ confidence interval of the bootstrap distribution did not include zero.

To investigate habitat differentiation, we classified sites into four groups (Table 2). The group $\mathrm{C}_{\mathrm{T}} \mathrm{S}_{\mathrm{T}}$ comprised sites where both species occurred at least once, but not necessarily within the same year. The groups $\mathrm{C}_{\mathrm{T}}$ and $\mathrm{S}_{\mathrm{T}}$ comprised sites where only C. russula (respectively, $S$. coronatus) was found at least once over the four years. Finally, the group $\mathrm{N}_{\mathrm{T}}$ comprised sites where none of the species were found during the whole survey. Subscript T refers to the site occupancy pattern over the four-year survey. Environmental variables were compared between sites $\mathrm{S}_{\mathrm{T}}, \mathrm{C}_{\mathrm{T}}$, and $\mathrm{C}_{\mathrm{T}} \mathrm{S}_{\mathrm{T}}$ using one-way MANOVA. Significance of pairwise comparisons between groups was evaluated with Tukey hsd post hoc tests.

To quantify possible habitat-specific differences in demographic parameters, we also contrasted C. russula colonization rate, extinction rate, occupancy, and density in sites where $\mathrm{S}$. coronatus was either present $\left(\mathrm{C}_{\mathrm{T}} \mathrm{S}_{\mathrm{T}}\right)$ or absent $\left(\mathrm{C}_{\mathrm{T}}\right)$, using bilateral Mann-Whitney tests. Symmetric analyses were performed on $S$. coronatus $\left(\mathrm{S}_{\mathrm{T}}\right.$ vs. $\mathrm{C}_{\mathrm{T}} \mathrm{S}_{\mathrm{T}}$ sites $)$.

To test for possible interactions between species, sites were classified according to yearly occupation: $\mathrm{C}_{1} \mathrm{~S}_{1}$ if both species co-occurred, $\mathrm{C}_{1} \mathrm{~S}_{0}$ (respectively, $\mathrm{C}_{0} \mathrm{~S}_{1}$ ) if only C. russula (respectively, S. coronatus) was found, and $\mathrm{C}_{0} \mathrm{~S}_{0}$ if both species were absent in the year being considered (Table 2). Exclusion was investigated by contrasting, for a given species, the suitability of unoccupied sites with the other species present, against unoccupied sites with the other species absent (i.e., $\mathrm{C}_{0} \mathrm{~S}_{0}$ vs. $\mathrm{C}_{0} \mathrm{~S}_{1}$ for $C$. russula, and $\mathrm{C}_{0} \mathrm{~S}_{0}$ vs. $\mathrm{C}_{1} \mathrm{~S}_{0}$ for $S$. coronatus). The rationale for this was that, if species $\mathrm{A}$ were excluding species B from otherwise favorable sites, then the suitability to B of sites inhabited only by A should exceed the suitability of unoccupied sites. The same analyses were also performed on the subsample of sites where both species occurred at least once $\left(\mathrm{C}_{\mathrm{T}} \mathrm{S}_{\mathrm{T}}, n=\right.$ 28).

\section{Temporal patterns}

To detect temporal exclusion, we also restricted analysis to those sites where both species were found in at least one year over the study period $\left(\mathrm{C}_{\mathrm{T}} \mathrm{S}_{\mathrm{T}}, n=28\right)$. Kappa statistics and significance levels were first calculated, with years considered as independent sampling units. We then tested whether the observed number of simultaneous co-occurrences differed from random expectation. Significance levels were tested through 10000 permutations of presence-absence data (independently for each species) within sites sampled for at least two consecutive years. Permutations, rather than bootstrapping, were used in this case because expected cooccurrences have to be calculated given observed frequencies. Co-occurrences were considered to differ significantly from random expectations if observed values were outside the $95 \%$ CI of the permutation distribution.

To detect specific differences in colonizing or competitive abilities, we tested in the same way whether successions differed from random (namely, whether colonization events by species A occurred preferentially in the absence of species $\mathrm{B}$, and whether extinction of species A occurred preferentially in the presence of species B).

All bootstrapping and permutation statistics were performed in R (R Development Core Team 2007).

\section{RESUlts \\ Field sampling}

Over the four years of the study, C. russula was found in 74 sites, with about one-half of the sites being occupied every year (33/62 in 2003, 40/84 in 2004, 44/84 in 2005, and 30/84 in 2006) (see Appendix for specific information). Altogether, 545 individuals were caught, with an average of $3.8 \pm 3.3$ individuals per occupied site (mean $\pm \mathrm{SD}$ ). Each marked individual was captured 1.70 times, on average, providing a rough estimation of capture probability per trapping session of $1.70 / 4=0.43$ (assuming equal trappability for all individuals within a garden). The probability of missing one individual over four trapping sessions was thus $(1-0.43)^{4}=0.11$, and that of missing both individuals of a breeding pair was $1 \%\left(0.11^{2}=0.011\right)$. No individual was recaptured over different sites or different years. Twenty-four colonizations (site empty in one year but occupied in the following year) out of 51 possible such events, and 40 extinctions (site occupied in one year but empty in the following year) out of 102 possible such events were 
TABle 3. MANOVA $P$ levels for differences in environmental variables between sites inhabited exclusively by $C$. russula or $S$. coronatus (respectively, $\mathrm{C}_{\mathrm{T}}$ and $\left.\mathrm{S}_{\mathrm{T}}\right)$ and by both species $\left(\mathrm{C}_{\mathrm{T}} \mathrm{S}_{\mathrm{T}}\right)$.

\begin{tabular}{lcccc}
\hline \hline \multicolumn{1}{c}{ Name } & Group effect & $\mathrm{C}_{\mathrm{T}}$ vs. $\mathrm{S}_{\mathrm{T}}$ & $\mathrm{C}_{\mathrm{T}}$ vs. $\mathrm{C}_{\mathrm{T}} \mathrm{S}_{\mathrm{T}}$ & $\mathrm{S}_{\mathrm{T}}$ vs. $\mathrm{C}_{\mathrm{T}} \mathrm{S}_{\mathrm{T}}$ \\
\hline BUILD & $* * *$ & $\mathrm{C}_{\mathrm{T}}>\mathrm{S}_{\mathrm{T}} * * *$ & $\mathrm{C}_{\mathrm{T}}>\mathrm{C}_{\mathrm{T}} \mathrm{S}_{\mathrm{T}} * * *$ & $\mathrm{~ns}$ \\
ELEV & $* * *$ & $\mathrm{C}_{\mathrm{T}}<\mathrm{S}_{\mathrm{T}} * * *$ & $\mathrm{C}_{\mathrm{T}}<\mathrm{C}_{\mathrm{T}} \mathrm{S}_{\mathrm{T}}$ & $\mathrm{ns}$ \\
EAST & $* * * *$ & $\mathrm{C}_{\mathrm{T}}<\mathrm{S}_{\mathrm{T}} * * *$ & $\mathrm{~ns}$ & $\mathrm{~ns}$ \\
FROST & $* * *$ & $\mathrm{C}_{\mathrm{T}}<\mathrm{S}_{\mathrm{T}} * * *$ & $\mathrm{C}_{\mathrm{T}}<\mathrm{C}_{\mathrm{T}} \mathrm{S}_{\mathrm{T}} * * *$ & $\mathrm{~ns}$ \\
NDVI & $\mathrm{ns}$ & $\mathrm{C}_{\mathrm{T}}<\mathrm{S}_{\mathrm{T}} * *$ & $\mathrm{C}_{\mathrm{T}}<\mathrm{C}_{\mathrm{T}} \mathrm{S}_{\mathrm{T}} * *$ & $\mathrm{~ns}$ \\
NORTH & $\mathrm{ns}$ & $\mathrm{C}_{\mathrm{T}}>\mathrm{C}_{\mathrm{T}} \mathrm{S}_{\mathrm{T}} * * *$ & $\mathrm{~ns}$ \\
WHAB & $\mathrm{ns}$ & $\mathrm{ns}$ & $\mathrm{ns}$ \\
WRAD & $* * *$ & $\mathrm{~ns}$ & & \\
Global effect (MANOVA) & & & \\
\hline
\end{tabular}

Notes: Significance levels of pairwise comparisons between groups were tested with Tukey hsd post hoc tests. MANOVA was used to text only the group effect. Levels of significance are: ${ }^{*} P<0.05 ; * * P<0.01 ; * * * P<0.001$. Variables for which $C$. russula prefers higher values than $S$. coronatus are indicated by $\mathrm{C}_{\mathrm{T}}>\mathrm{S}_{\mathrm{T}}$, and those where lower values are preferred by $\mathrm{C}_{\mathrm{T}}<\mathrm{S}_{\mathrm{T}}$.

detected during the survey, so that colonization and extinction rates can be estimated as $0.47 \mathrm{yr}^{-1}$ and 0.39 $\mathrm{yr}^{-1}$, respectively.

Sorex coronatus was less abundant, with 50 sites occupied at least once over the four years (21/62 in 2003, $21 / 84$ in 2004, 24/84 in 2005, and 26/84 in 2006). In total, 182 individuals were caught (average $2.0 \pm 1.3$ individuals per occupied site). Each marked individual was captured 1.58 times, on average, providing a rough estimation of capture probability per trapping session of $1.58 / 4=0.39$. The probability of missing one individual over four trapping sessions was thus $(1-0.39)^{4}=0.13$, and that of missing both individuals of a breeding pair was less than $2 \%\left(0.13^{2}=0.017\right)$. During the study, 29 colonizations (out of 60 possible events) and 31 extinctions (out of 63 possible events) occurred, so that colonization and extinction rates amounted to $0.48 \mathrm{yr}^{-1}$ and $0.49 \mathrm{yr}^{-1}$, respectively.

Neither colonization nor extinction rates differed significantly between the two species $(P$ values $=1.00$ for colonization and 0.27 for extinction, using binomial tests to compare two proportions; Crawley [2005:84]). Out of the 106 sites investigated, 28 were occupied by both species, and simultaneously so in 18 instances (Table 2). Other potential competitors can be safely neglected in the analysis, since only five individual shrews from two other species (four Neomys fodiens and one Sorex minutus) were captured over the four years of the study.

\section{Habitat analyses}

The ENFA habitat model for $C$. russula was built with four axes, explaining $100 \%$ of the marginality and $82 \%$ of the specialization. The scores for environmental variables (Table 1) indicate a strong preference for human settlements (density of buildings and heated habitations). Solar radiation and altitude also play a role in niche specialization. The fit was excellent, as quantified by a very high Boyce index with a low variance $(0.88 \pm 0.07$, mean $\pm \mathrm{SD})$.

The habitat model for $S$. coronatus was built with five axes, explaining $100 \%$ of the marginality and $87 \%$ of the specialization. The scores for environmental variables
(Table 1) point to similar requirements, with some preferences for human settlements and specialization on altitude. The fit was also excellent, with a continuous Boyce index amounting to $0.86 \pm 0.07$ (mean $\pm \mathrm{SD}$ ).

\section{Habitat differentiation and exclusion}

The kappa index estimated over all sites pointed to a significant discrimination between the two species $(\kappa=$ -0.27 ; 95\% CL $[-0.39,-0.16]$ ) (kappa values were also significant for each year when analyzed separately). Environmental variables appear to globally differ between sites occupied exclusively by $C$. russula $\left(\mathrm{C}_{\mathrm{T}}\right)$ or $S$. coronatus $\left(\mathrm{S}_{\mathrm{T}}\right)$ and by both species $\left(\mathrm{C}_{\mathrm{T}} \mathrm{S}_{\mathrm{T}}\right)$ (MANOVA, $P<0.0001$; Table 3). A comparison between sites occupied exclusively by $C$. russula or $S$. coronatus $\left(\mathrm{C}_{\mathrm{T}}\right.$ vs. $\left.\mathrm{S}_{\mathrm{T}}\right)$ revealed habitat differentiation on six environmental variables, with $C$. russula showing a stronger preference for human settlements, lower elevation, and more open and warmer sites.

Comparison of $C$. russula sites with vs. without $S$. coronatus $\left(\mathrm{C}_{\mathrm{T}} \mathrm{S}_{\mathrm{T}}\right.$ vs. $\left.\mathrm{C}_{\mathrm{T}}\right)$ similarly revealed a preference for human settlements and warmer sites at lower elevations. In contrast, a comparison of $S$. coronatus sites with vs. without $C$. russula $\left(\mathrm{C}_{\mathrm{T}} \mathrm{S}_{\mathrm{T}}\right.$ vs. $\left.\mathrm{S}_{\mathrm{T}}\right)$ revealed no significant differences. Furthermore, C. russula-free sites were not more suitable for $C$. russula in the presence of $S$. coronatus (Mann-Whitney tests: for all sites, $P=0.91$; restricted to sites where both species occurred, $P=0.69$ ). $S$. coronatus-free sites were not more suitable for $S$. coronatus in the presence of $C$. russula (Mann-Whitney tests: for all sites, $P=0.98$; restricted to sites where both species occurred, $P=0.80$ ).

The density and occupancy rate of $C$. russula (respectively, $S$. coronatus) were significantly higher in sites unoccupied by the other species (respectively, $\mathrm{C}_{\mathrm{T}}$ or $\left.\mathrm{S}_{\mathrm{T}}\right)$ than in sites favorable for both species $\left(\mathrm{C}_{\mathrm{T}} \mathrm{S}_{\mathrm{T}}\right)($ Table 4; $P<0.0002$ for the four comparisons). Extinction rates were also significantly higher in sites favorable to both species $\left(\mathrm{C}_{\mathrm{T}} \mathrm{S}_{\mathrm{T}}\right)$ than in sites inhabited only by the focal species (Table 4; C. russula, $P=0.005 ; S$. coronatus, $P=0.01)$. Reciprocally, colonization rate for $C$. russula was significantly higher in sites unoccupied by $S$. coronatus $\left(\mathrm{C}_{\mathrm{T}}\right)$ than in sites favorable for both 
TABLE 4. Mean values of demographic variables (density, occupancy, colonization, and extinction rates) generally differ between sites occupied either by the focal species (C. russula, $\mathrm{C}_{\mathrm{T}}$; or $S$. coronatus, $\left.\mathrm{S}_{\mathrm{T}}\right)$ or by both species $\left(\mathrm{C}_{\mathrm{T}} \mathrm{S}_{\mathrm{T}}\right)$.

\begin{tabular}{|c|c|c|c|c|c|c|}
\hline \multirow[b]{2}{*}{ Variable } & \multicolumn{2}{|c|}{ C. russula mean for sites } & \multirow[b]{2}{*}{$P$} & \multicolumn{2}{|c|}{ S. coronatus mean for sites } & \multirow[b]{2}{*}{$P$} \\
\hline & $\mathrm{C}_{\mathrm{T}}$ & $\mathrm{C}_{\mathrm{T}} \mathrm{S}_{\mathrm{T}}$ & & $\mathrm{S}_{\mathrm{T}}$ & $\mathrm{C}_{\mathrm{T}} \mathrm{S}_{\mathrm{T}}$ & \\
\hline Occupancy & 0.80 & 0.48 & 0.001 & 0.73 & 0.42 & 0.0001 \\
\hline Density & 3.3 & 1.54 & $<0.0001$ & 1.58 & 0.70 & 0.0002 \\
\hline Colonization rate & 0.70 & 0.39 & 0.037 & 0.50 & 0.52 & 0.89 \\
\hline Extinction rate & 0.37 & 0.69 & 0.005 & 0.42 & 0.77 & 0.01 \\
\hline
\end{tabular}

Note: Given are $P$ values for the differences among groups (bilateral Mann-Whitney tests).

species $\left(\mathrm{C}_{\mathrm{T}} \mathrm{S}_{\mathrm{T}} ; P=0.037\right)$, but there was no such effect for $S$. coronatus.

Considering only the sites where both species occurred $\left(\mathrm{C}_{\mathrm{T}} \mathrm{S}_{\mathrm{T}}\right)$, we found no suggestion of temporal exclusion. Kappa values were significant neither over all years $(\kappa=$ -0.04 ; 95\% CL $[-0.23,0.16])$ nor for each year separately, and simultaneous occupation did not occur significantly less than random expectation. The observed value was 18 times when both species were found in the same site within the same year over the study period; 95\% CL under random expectation: [15, 24]; the maximum value would be 314 (total sites samples in four years) if both species were always present in each of the sites. Similarly, the patterns of temporal succession in sites where both species co-occurred did not deviate significantly from random: neither of the two species was more likely to settle in the absence of the other species (Fisher tests: C. russula, $P=0.70, n=44 ; S$. coronatus, $P=0.34, n=70$ ), or more likely to become extinct in the presence of the other species (Fisher tests: C. russula, $P=1, n=28 ; S$. coronatus, $P=0.61, n=42)$. Here, $n$ represents the number of annual transitions from an occupied to an unoccupied site (for extinction) and from an empty to an occupied site (for colonization). These transitions were recorded only on sites where both species were found over the four-year study (but not necessarily within the same year, i.e., $\mathrm{C}_{\mathrm{T}} \mathrm{S}_{\mathrm{T}}$ ). Results remained unchanged when considering the presence of the other species in the year before the transition ( $P$ values ranged from 0.45 to 1.0$)$.

\section{DisCusSION}

The two shrew species co-occurred in 28 of the 106 localities investigated, pointing to an important habitat overlap and a large scope for competition. However, this number was less than that expected by chance, obtained as the product of specific occurrence probabilities $(74 \times$ $50 / 106=35)$. Accordingly, the kappa index was significantly negative.

From our analyses, this deficit in co-occurrences mostly stemmed from a habitat differentiation. Although preferences seem broadly similar and distributions seem to be affected by the same environmental variables, the two species were specializing on slightly different values. A comparison of sites occupied exclusively by one or the other species $\left(\mathrm{C}_{\mathrm{T}}\right.$ vs. $\left.\mathrm{S}_{\mathrm{T}}\right)$ revealed that $C$. russula preferred warmer sites at lower elevation, with less vegetation and closer to winterheated human habitations. The same results emerged when comparing $C$. russula sites with and without $S$. coronatus $\left(\mathrm{C}_{\mathrm{T}} \mathrm{S}_{\mathrm{T}}\right.$ vs. $\left.\mathrm{C}_{\mathrm{T}}\right)$ : C. russula sites were warmer, at lower elevation, with less vegetation and closer to human habitations. The reverse comparison $\left(\mathrm{C}_{\mathrm{T}} \mathrm{S}_{\mathrm{T}}\right.$ vs. $\mathrm{S}_{\mathrm{T}}$ ) revealed no significant differences, possibly because our sampling design focused on localities a priori favorable to $C$. russula (human habitations), thereby ignoring a fraction of $S$. coronatus habitat. These differences in habitat quality translated into differences in demography: C. russula displayed higher density, occupation, and colonization rates, as well as a lower extinction rate, in pure $C$. russula sites $\left(\mathrm{C}_{\mathrm{T}}\right)$ than in sites also favorable to $S$. coronatus $\left(\mathrm{C}_{\mathrm{T}} \mathrm{S}_{\mathrm{T}}\right)$. The reverse also applied to $S$. coronatus, except for colonization rate. Our data thus provide evidence that habitat differentiation (even though incomplete) mediates regional coexistence in these competing species. This argues in favor of the species-sorting and mass-effect paradigms, but against the neutral and patch-dynamics paradigms, which assume undifferentiated habitat use.

Furthermore, we argue that the patterns of local coexistence and temporal occupation tend to favor the mass-effect against the species-sorting paradigm. Indeed, the latter assumes that local dynamics occur on shorter time scales than regional dynamics, so that locally favored species have ample time to exclude competitors (Leibold et al. 2004), although competitive exclusion is not necessarily required for species sorting. This should leave little scope for local coexistence, and should induce a close match between species distributions and habitat conditions. Under the mass-effect perspective, by contrast, immigration and emigration affect local population dynamics, so that species can be rescued from local competitive exclusion in communities where they are bad competitors by immigrants from communities where they are good competitors (Leibold et al. 2004). Accordingly, we found substantial numbers of local co-occurrences (28 mixed sites out of 106 , with simultaneous occurrence in 18 instances) and no support for competitive exclusion. No species excluded its competitor from otherwise suitable sites, and the sites occupied by both species showed no sign of temporal exclusion (the patterns of temporal occupation and succession did not differ from random). Furthermore, the rates of extinction and colonization documented 
here point to similar time scales for regional and local processes. The characteristic times to extinction of occupied sites (obtained as the inverse of extinction rate) were indeed very short, less than three years in both species (2.55 years for $C$. russula and 2.03 for $S$. coronatus). In addition, a parallel analysis of $C$. russula dynamics in this same metapopulation (Jaquiéry et al., in press) showed that local population sizes were significantly affected by the connectivity to potential source populations and by the quality of these sources, confirming important mass effects in the system under study.

Because our sampling design focused a priori on $C$. russula sites, the niche of $S$. coronatus might have remained partly unsampled. Assuming that better quality $S$. coronatus habitat exists outside human habitations, sampling this habitat would have resulted in a lower kappa index (because species would then cooccur in a lower proportion of sites), a stronger niche differentiation, and possibly lower extinction rate and higher colonization rates for this species. However, our main conclusion (namely that mass effects mediate coexistence in our study system) would have remained unchanged. The additional data would have argued more strongly against the patch-dynamics and neutral paradigms (because these models assume no habitat differentiation), and the patterns of local coexistence documented here would still support the mass effect (against the species-sorting) paradigm.

The landscape under study displays spatial autocorrelation of environmental variables (e.g., elevation, number of frost days), so that the sites favorable to one species tend to be somewhat aggregated. Such spatial structures are expected to affect local dynamics (be it only because dispersal range is limited), but there is no simple way to analyze such effects. However, we note that this feature only reinforces our main conclusion (namely that coexistence is mediated by mass effects). First, the neutral and patch-dynamics models assume no habitat differentiation, and therefore no landscape structure. Habitat heterogeneity and spatial structure are, by contrast, constitutive parts of the species-sorting and mass-effect paradigms. Second, the main effect of spatial structure is to lower the opportunity for local coexistence (because dispersing individuals are more likely to settle in sites already occupied by conspecifics), and thereby the power to detect mass effect. Neglecting spatial aspects in our analyses is thus conservative regarding our main conclusion.

Observations by previous authors (Croin-Michielsen 1966, Genoud 1985; see Methods) suggested a patchdynamics component, in which one species ( $S$. coronatus) would benefit from its ability to colonize empty sites, and the other ( $C$. russula) from its ability to exclude competitors. We found no evidence for such a component. Extinction and colonization rates were similar (although estimations for $S$. coronatus might be biased due to our sampling design), and the patterns of temporal successions in sites suitable for both species did not differ from random. In particular, S. coronatus was not more likely than $C$. russula to settle in empty sites or to be excluded from occupied sites. The only asymmetry noticed (namely, sparser and smaller populations in $S$. coronatus) was more likely to result from the asymmetry in the sampling design, which focused on sites a priori favorable to C. russula.

Altogether, spatial and temporal patterns point to a mass-effect scenario in which regional coexistence is mediated by specialization on different habitat types, while local coexistence is maintained by recurrent dispersal from source habitats. A general role of habitat heterogeneity in maintaining regional coexistence of competing species seems well supported both theoretically (Chesson 2000a, b, Amarasekare 2003, Mouquet and Loreau 2003) and empirically (Codeco and Grover 2001, Yu et al. 2001). By contrast, the role of mass effects in maintaining local diversity seems less documented. A recent meta-analysis by Cottenie (2005) suggests that a majority of published metacommunity data sets are structured by species-sorting processes (44\%), followed by a combination of SS and mass-effects (29\%), vs. less than $10 \%$ for neutral or patch-dynamics processes. This meta-analysis also points to significant effects of dispersal abilities and spatial scale of the study area on metacommunity structuring.

In our own study, the high dispersal abilities of both species, combined with the relatively small spatial scale involved $(6 \times 14 \mathrm{~km})$ and the high regional dynamics, certainly concurred to generate important mass effects. Extinction and colonization rates were particularly high because both species were living here in marginal conditions, at the altitudinal limit of their distributions. Consequences are twofold. First, environmental stochasticity certainly exceeded the levels normally experienced in core areas (Guo et al. 2005, Holt et al. 2005). At this altitude, a strong winter might easily wipe out a series of local populations. Second, local populations were small (3.8 \pm 3.3 individuals captured per site for $C$. russula and $2.0 \pm 1.3$ for $S$. coronatus), normally not exceeding one pair with their progeny, which further induces high levels of demographic stochasticity through the random nature of individual survival, fecundity, and dispersal.

Frequent extinctions may not only select for high dispersal, but also maintain local populations below their carrying capacities for substantial periods of time. Competitive exclusions should not occur as long as populations are not limited by resources. Demographic stochasticity, furthermore, makes the outcome of competitive interactions less predictable, because random events may override possible differences in competitive ability, rendering interactions effectively neutral (Orrock and Fletcher 2005). These blurring effects should lower the match between species distri- 
bution and environmental conditions, and enhance the scope for spatial effects.

\section{ACKNOWLEDGMENTS}

We would like to thank Caroline Colliard, Antoine Burnier, and Sébastien Stücki for their help during field sampling; Patrick Basset and Glenn Yannic for the genetic identification of S. coronatus; Christophe Randin, Gwenaëlle Le Lay, and Thomas Czaka for helpful discussions of GIS analyses; Jonathan Yearsley, Jérôme Chave, and two anonymous referees for valuable comments on a previous draft of this manuscript. We are grateful to the many "Combiers" who allowed us trapping in their gardens. The Swiss National Science Foundation provided financial support (grant 3100A0-108100 to N. Perrin)

\section{Literature Cited}

Amarasekare, P. 2003. Competitive coexistence in spatially structured environments: a synthesis. Ecology Letters 6: 1109-1122.

Bever, K. 1983. Zur Nahrung der Hausspitzmaus, Crocidura russula (Hermann, 1780). Säugetierkundliche Mitteilungen 31:13-26.

Bouteiller, C., and N. Perrin. 2000. Individual reproductive success and effective population size in the greater whitetoothed shrew Crocidura russula. Proceedings of the Royal Society B 267:701-705.

Brotons, L., W. Thuiller, M. B. Araujo, and A. H. Hirzel. 2004. Presence-absence versus presence-only modelling methods for predicting bird habitat suitability. Ecography 27:437-448.

Butet, A., G. Paillat, and Y. Delettre. 2006. Seasonal changes in small mammal assemblages from field boundaries in an agricultural landscape of western France. Agriculture Ecosystems and Environment 113:364-369.

Castien, E., and G. Gosalbez. 1995. Diet of Sorex coronatus in the Western Pyrenees. Acta Theriologica 40:113-121.

Chase, J. M., and M. A. Leibold. 2003. Ecological niches: linking classical and contemporary approaches. University of Chicago Press, Chicago, Illinois, USA.

Chefaoui, R. M., J. Hortal, and J. M. Lobo. 2005. Potential distribution modelling, niche characterization and conservation status assessment using GIS tools: a case study of Iberian Copris species. Biological Conservation 122:327-338.

Chesson, P. 2000a. Mechanisms of maintenance of species diversity. Annual Review of Ecology and Systematics 31: 343-367.

Chesson, P. 2000b. General theory of competitive coexistence in spatially varying environments. Theoretical Population Biology 58:211-237.

Churchfield, S. 1990. The natural history of shrews. Comstock Publishing Associates, Cornell University Press, Ithaca, New York, USA.

Codeco, C. T., and J. P. Grover. 2001. Competition along a spatial gradient of resource supply: a microbial experimental model. American Naturalist 157:300-315.

Cohen, J. 1960. A coefficient of agreement of nominal scales. Educational and Psychological Measurement 20:37-46.

Cottenie, K. 2005. Integrating environmental and spatial processes in ecological community dynamics. Ecology Letters 8:1175-1182.

Cottenie, K., E. Michels, N. Nuytten, and L. De Meester. 2003. Zooplankton metacommunity structure: regional vs. local processes in highly interconnected ponds. Ecology 84:9911000.

Crawley, M. 2005. Statistics, an introduction using R. John Wiley, Chichester, UK.

Croin Michielsen, N. 1966. Intraspecific competition in the shrews Sorex araneus L. and S. minutus L. Archives Néerlandaises de Zoologie 17:73-174.
Engler, R., A. Guisan, and L. Rechsteiner. 2004. An improved approach for predicting the distribution of rare and endangered species from occurrence and pseudo-absence data. Journal of Applied Ecology 41:263-274.

Favre, L., F. Balloux, J. Goudet, and N. Perrin. 1997. Femalebiased dispersal in the monogamous mammal Crocidura russula: evidence from field data and microsatellite patterns. Proceedings of the Royal Society B 264:127-132.

Fielding, A. H., and J. F. Bell. 1997. A review of methods for the assessment of prediction errors in conservation presence/ absence models. Environmental Conservation 24:38-49.

Genoud, M. 1982. Distribution écologique de Crocidura russula et Sorex coronatus (Soricidae, Mammalia) en Suisse romande. Bulletin de la Société vaudoise des sciences naturelles 76:117-132.

Genoud, M. 1985. Ecological energetics of two European shrews: Crocidura russula and Sorex coronatus (Soricidae, Mammalia). Journal of Zoology 207:63-85.

Genoud, M., and J. Hausser. 1979. Ecology of a Crocidura russula population in a rural mountain habitat. Terre et Vie 33:539-554.

Guo, Q. F., M. Taper, M. Schoenberger, and J. Brandle. 2005. Spatial-temporal population dynamics across species range: from centre to margin. Oikos 108:47-57.

Hastie, T., R. Tibshirani, and J. H. Friedman. 2001. The elements of statistical learning: data mining, inference, and prediction. Springer-Verlag, New York, New York, USA.

Hausser, J. 1995. Mammifères de la Suisse. Commission des mémoires de l'académie suisse des sciences naturelles, Basel, Switzerland.

Hirzel, A. H., J. Hausser, D. Chessel, and N. Perrin. 2002. Ecological-niche factor analysis: how to compute habitatsuitability maps without absence data? Ecology 83:20272036.

Hirzel, A. H., J. Hausser, and N. Perrin. 2004a. Biomapper 3.1. Statistical software. A GIS-toolkit to model ecological niche and habitat suitability. Laboratory for Conservation Biology, University of Lausanne, Switzerland. 〈http://www2.unil. ch/biomapper/>

Hirzel, A. H., V. Helfer, and F. Métral. 2001. Assessing habitatsuitability models with a virtual species. Ecological Modelling 145:111-121.

Hirzel, A. H., B. Posse, P.-A. Oggier, Y. Crettenand, C. Glenz, and R. Arlettaz. 2004b. Ecological requirements of a reintroduced species, with implications for release policy: the bearded vulture recolonizing the Alps. Journal of Applied Ecology 41:1103-1116.

Hirzel, A. H., G. Le Lay, V. Helfer, C. Randin, and A. Guisan. 2006. Evaluating the ability of habitat suitability models to predict species presences. Ecological Modelling 199:142-152.

Holt, R. D. 1993. Ecology at the mesoscale: the influence of regional processes on local communities. Pages 77-88 in R. Ricklefs and D. E. Schluter, editors. Species diversity in ecological communities: historical and geographical perspectives. Chicago University Press, Chicago, Illinois, USA.

Holt, R. D., T. H. Keitt, M. A. Lewis, B. A. Maurer, and M. L. Taper. 2005. Theoretical models of species' borders: single species approaches. Oikos 108:18-27.

Holyoak, M., M. A. Leibold, and R. D. Holt. 2005. Metacommunities: spatial dynamics and ecological communities. Chicago University Press, Chicago, Illinois, USA.

Hubbell, S. P. 2001. The unified neutral theory of biodiversity and biogeography. Princeton University Press, Princeton, New Jersey, USA.

Indelicato, N. 2000. Aspects biogéographiques de la distribution des micromammifères dans la Limousin. Annales scientifiques du Limousin 11:61-79.

Jaquiéry, J., J. Guélat, T. Broquet, L. Berset-Brändli, E. Pellegrini, R. Moresi, A. H. Hirzel, and N. Perrin. In press. Habitat-quality effects on metapopulation dynamics in the 
greater white-toothed shrew (Crocidura russula). Ecology XX: XXXXXXX.

Leibold, M. A. 1998. Similarity and local co-existence of species in regional biotas. Evolutionary Ecology 12:95-110.

Leibold, M. A., M. Holyoak, N. Mouquet, P. Amarasekare, J. M. Chase, M. F. Hoopes, R. D. Holt, J. B. Shurin, R. Law, D. Tilman, M. Loreau, and A. Gonzalez. 2004. The metacommunity concept: a framework for multi-scale community ecology. Ecology Letters 7:601-613.

Leibold, M. A., and J. Norberg. 2004. Biodiversity in metacommunities: Plankton as complex adaptive systems? Limnology and Oceanography 49:1278-1289.

Levin, S. A. 1974. Dispersion and population interactions. American Naturalist 108:207-228.

Levins, R., and D. Culver. 1971. Regional coexistence of species and competition between rare species (mathematical model/habitable patches). Proceedings of the National Academy of Sciences (USA) 68:1246-1248.

Lotka, A. 1924. Elements of physical biology. Williams and Wilkins, Baltimore, Maryland, USA.

Mouquet, N., and M. Loreau. 2002. Coexistence in metacommunities: the regional similarity hypothesis. American Naturalist 159:420-426.

Mouquet, N., and M. Loreau. 2003. Community patterns in source-sink metacommunities. American Naturalist 162:544 557.
Orrock, J. L., and R. J. Fletcher. 2005. Changes in community size affect the outcome of competition. American Naturalist 166:107-111.

Pulliam, H. R. 2000. On the relationship between niche and distribution. Ecology Letters 3:349-361.

R Development Core Team. 2007. R: a language and environment for statistical computing. R Foundation for Statistical Computing, Vienna, Austria.

Reutter, B. A., V. Helfer, A. H. Hirzel, and P. Vogel. 2003. Modelling habitat-suitability on the basis of museum collections: an example with three sympatric Apodemus species from the Alps. Journal of Biogeography 30:581-590.

Rouse, J. W., R. H. Haas, J. A. Schell, and D. W. Deering. 1973. Monitoring vegetation systems in the Great Plains with ERTS. Third ERTS Symposium, NASA SP-351 I:309-317.

Shmida, A., and M. V. Wilson. 1985. Biological determinants of species diversity. Journal of Biogeography 12:1-20.

Tilman, D. 1994. Competition and biodiversity in spatially structured habitats. Ecology 75:2-16.

Volterra, V. 1926. Fluctuations in the abundance of a species considered mathematically. Nature 118:558-560.

Yu, D. W., H. B. Wilson, and N. E. Pierce. 2001. An empirical model of species coexistence in a spatially structured environment. Ecology 82:1761-1771.

\section{APPENDIX}

A table showing coordinates, number of trapped Crocidura russula and Sorex coronatus individuals, and habitat suitability for each site, 2003-2006 (Ecological Archives XXXXXXXXXX). 